\title{
Can Recovery of Bone Mineral Density at the Fracture Site in the Distal Radius Be Used As a Measure of Fracture Healing
}

\author{
Ashraf Awad*, JG Andrew, C Williams and C Hutchinson \\ University of Manchester, England
}

Submission: February 06, 2018; Published: March 05, 2018

*Corresponding author: Ashraf Awad, Torbay Hospital, Torbay and South Devon Healthcare Foundation Trust, UK,

Emai: dr_ashrafawad@yahoo.co.uk

Abstract

Metaphyseal fractures (especially in the elderly) are now commonest type of fracture. Bone mineral density (BMD) of the fracture callus has been used as a measure of healing in diaphyseal fractures. This study investigated whether measurement of BMD at the fracture site in the distal radius can be used as a measure of fracture healing. 28 patients with dorsally displaced distal radial fracture were treated by intrafocal wire fixation. All patients had acceptable correction of dorsal and radial angle at final x-ray ( 3 months). BMD was measured at the fracture site (examining the BMD of the medullary bone at the fracture site after removal of wires), in the opposite wrist and the lumbar spine using QCT at 6 weeks after fracture.

Wrist function was measured using Patient Rated Wrist Evaluation (PRWE - a validated outcome measured for use after distal radial fractures, grip strength, and range of motion at 6,12 and 26 weeks. We found no correlation between recoveries of grip strength (\% of contra lateral grip strength) at 6,12, or 26 weeks with BMD at either site. Similarly, there was no correlation between BMD and either absolute PRWE scores at any time point or improvement in PRWE between time points. The strongest predictor of recovery of grip appeared to be the proportion of grip recovered at 6 weeks (correlation between $\%$ grip recovered at 6 weeks and 3 months $r=0.85$; at 6 weeks adn 6 months $r=0.56$; both $\mathrm{p}>0.001$ ). This was not affected by age or variations in measured angle or length within this group. It was not affected by degree of preoperative fracture displacement. These data suggest that recovery of function after distal radial fractures is not influenced by osteoporosis and the data about the importance of initial recovery of grip suggest that factors other than bone position and bone healing may affect rate of functional recovery after distal radial fracture.

Keywords: Functional recovery; Fracture healing; Fracture BMD

\section{Introduction}

The formation of callus is the natural repair and fixation response to a fracture in the absence of artificial fixating devices including casts or osteosynthetic materials. Callus response is also an expression of fracture healing [1,2] and by numerically measuring the amount of callus, it is possible to quantify the healing process. Osteoporosis can be defined as a disease with low bone mass and microarchietectural deterioration of bone tissue, leading to enhanced bone fragility [3]. Currently the clinical diagnosis of osteoporosis is based on the measurement of bone mineral density (BMD) alone using energy X-ray absorptiometry (DXA) but does not account for spatial distribution and inherent material properties of the tissue. Peripheral quantative computed tomography ( $\mathrm{pQCT}$ ) permits one to measure the compartment specific density and geometry based on parameters of cortical bone [4].
$\mathrm{AB}$ fracture distal radius (and ulna) is a manifestation of Osteoporosis and the incidence in middle aged and elderly especially women is high [5-7] and bone mineral density (BMD) decreases with advancing age and the incidence of distal radius fractures increases [8]. Our study Aimed to establish the relation between rate of recovery (BMD) and bone healing process, the influence of the BMD on the clinical results and whether this influence would affect the fracture healing process.

\section{Methods}

28 Patients with dorsally displaced distal radial fractures were treated by intrafocal wire fixation. All patients had acceptable correction of dorsal and radial angle at final x-ray (3 months). BMD was measured at the fracture site (examining the BMD of the medullary bone at the fracture site after removal of wires), in the opposite wrist and the lumbar spine using QCT at 
6 weeks after fracture. Wrist function was measured using the Patient Rated Wrist Evaluation (PRWE - a validated outcome measure for use after distal radial fractures), grip strength, and range of motion at 6,12 and 26 weeks.

The plan of work was first is to measure the spine BMD of all patients and to relate (correlate vs. regression) spine BMD to recovery of PREW, 1) vs. Absolute BMD (T score) and 2) vs Z score. This might answer whether the fracture healing defined by functional recovery affected by osteoporosis (defined by Tscore or Z score). Second is to measure the normal wrist BMD of all patients and to relate it as well to the recovery of PRWE, which in turn might answer is recovery of wrist function after fracture related to the Pre \# wrist BMD; expect recovery to be worse with low BMD (slower healing due to poor bone health) or worse with high BMD (requires higher energy for \#)?

Third is to measure the spine BMD on second visit, to see whether if the spine measurements are consistent or not? Fourth measuring the fractured wrist BMD and the relation of the fractured wrist to the normal visit BMD vs. PRWE recovery to assess effect of degree of compression on recovery (degree of compression as marker of injury severity), at 6 weeks fractured wrist/normal wrist vs. PRWE recovery to assess wrist \# BMD on recovery, change in fractured wrist BMD at 6 weeks to 12 weeks vs. recovery of PRWE and finally change of fractured wrist between first and second CT's.

Fifth is measuring the angles were Relationship between 1) fracture at six weeks and 2) normal wrist BMD on 1) preoperative angles; 2) 6/52 angles; 3) loss of angles between 6 and 12 weeks, Within PRWE, we considered 1) global PRWE; 2) pain domains 3) chair and rolb lift. We looked at loss of length 1) pre operative 2) final 3) post operative minus final vs. 1) degree of impaction on CTs (\#BMD) 2) normal wrist BMD.

\section{Results}

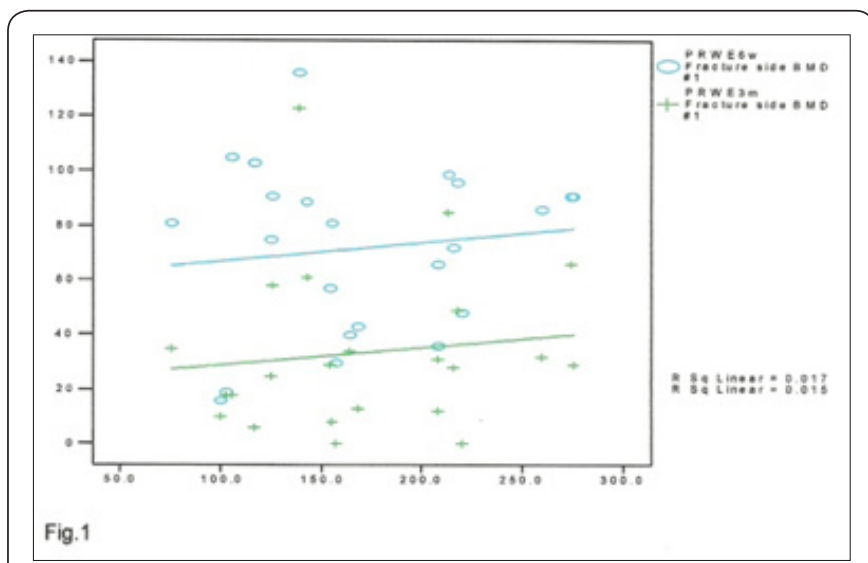

Figure 1: The BMD at the fracture site was higher than the BMD at the other wrist (mean 168 vs $70 \mathrm{HU} ;<0.001$ paired T test).

We have found that there is no correlation between BMD at the fracture site and BMD at the other wrist or lumbar spine (r-co.g), The BMD at the fracture site was higher than the BMD at the other wrist (mean 168 vs. $70 \mathrm{HU} ;<0.001$ paired $\mathrm{T}$ test) (Figure 1), There was no relationship between fracture site BMD or the ratio of BMDs fracture site/normal wrist, and any of the functional assessments (proportion grip strength recovered, range of motion or PRWE (r-co.g). 15 of these patients underwent a second QCT at 12 weeks after fracture. There was no significant change in fracture site BMD between first and second scan. Similarly, there was no correlation between BMD and either absolute PRWE scores at any time point or improvement in PRWE between time points (Figure 2).

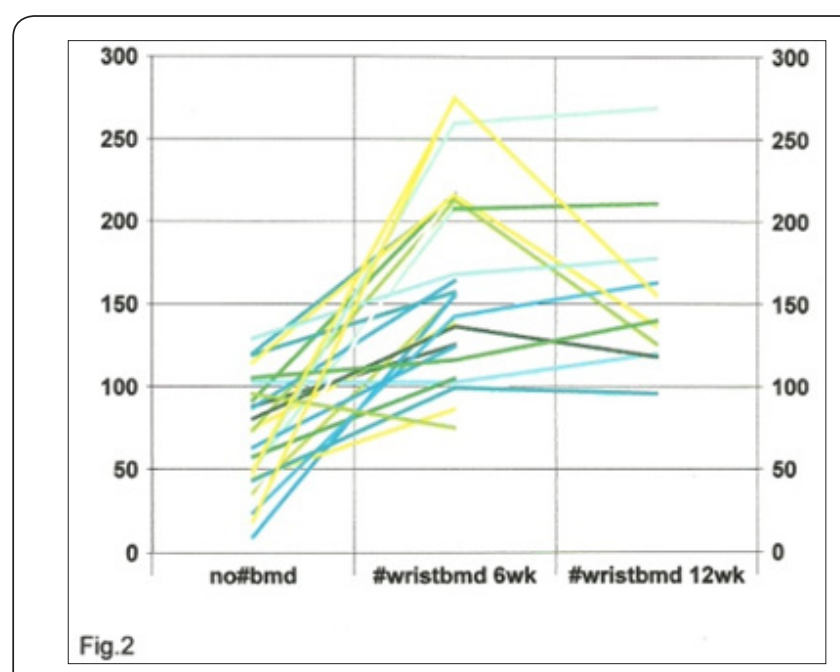

Figure 2 : No correlation between BMD and either absolute PRWE scores at any time point or improvement in PRWE between time points.

\section{Discussion}

We had anticipated that progression of bone healing between 6 and 12 weeks would have been associated with an increase in BMD; in the even this was not what we found. Further, the finding that the BMD at the fracture site was higher than that at the normal wrist was a suprise. BMD of endosteal callus does not seem likely to be helpful as a measure of meaphyseal fracture healing in future research. This is indicated both by the lack of progression of BMD, and the fact that fracture site BMD in higher than the normal wrist. Two possible explanations at proposed: The majority of stiffness recovered initially in metaphyseal fractures may be due to cortical healing. This study did not examine cortical healing; our scans had a $5 \mathrm{~mm}$ slice thickness, which would not permit examination of the relatively narrow cortical callus or the recovery of stiffness between 6 and 12 weeks in metaphyseal fractures may be due remodelling of woven to mature bone, rather than additional mineralization of callus. This would suggest that measurement of endosteal BMD.

Before 6 weeks might be useful in measuring healing. We suggest that further research using pQCT at thinner slice thickness and at an earlier point after fracture would help establish whether mineralization of endoseal callus is critical to recovery of fracture stiffness at an early stage after metaphyseal fracture. This will be important to determine whether use of 
endosteal growth factors are likely to accelerate fracture healing in a useful fashion in metaphyseal fractures. These data indicate that fracture site BMD is unlikely to be a useful method of measuring bone healing. This was different than the results of Hollevoet et al. [9].

\section{References}

1. Chapman MW (2001) Closed treatment of fractures and dislocations. In: Chapman (Ed.), MW Chapman's Orthopaedic Surgery, (3 $3^{\text {rd }}$ edn). Lippincott Williams, and Wilkins, Philadelphani, USA, pp. 228-229.

2. McKibbin B (1982) Repair of fractures. In: Wilson JN (Ed.), WatsonJones Fracture and Joint Injuries. Churchill Livinstione, Edinburgh, Scotland, p. 14-28.

3. World Health Organisation (1994) Assessment of fracture risk and its application to screening for postmenopausal osteoporosis. Report of World Health Organization Study Group. WHO Technical Report Series 843: 1-129.

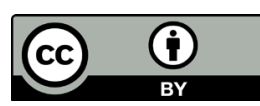

This work is licensed under Creative Commons Attribution 4.0 License DOI: $10.19080 /$ OROAJ.2018.10.555798
4. Hudelmaier M, Kuhn V, Lochmuller EM, Well H, Priemel M, et al. (2004) Can geometry-based parameters from pQCT and material parameters from quantitative ultrasound ( QUS) improve the prediction of radial bone strength over that by bone mass (DXA). Osteoporosis Int 15(5): 375-381.

5. Riggs BL, Melton LJ (1986) Involutional osteoporosis. N Engl J Med 314(26): 1676-1686

6. Eastell R, Riggs BL, Wahner HW, O'Fallon WM, Amadio PC, et al. (1989) Colles' fracture and bone density of the ultradistal radius. J Bone Miner Res 4(4): 607-613.

7. Mallmin H, Ljunghall S (1994) Distal radius fracture is an early sign of general osteoporosis: bone mass measurements in a population based study. Osteoporosis Int 4(6): 357-361.

8. Lane JM, Ruse L, Khan SN (2000) Osteoporosis. Clin Orthop 372: 139150 .

9. Hollevoet N, Verdonk R (2003) outcome of distal radius fracture in relation to bone mineral density. Acta Orthopaedica Belgica 69(6): 510-514.

\section{Your next submission with Juniper Publishers will reach you the below assets}

- Quality Editorial service

- Swift Peer Review

- Reprints availability

- E-prints Service

- Manuscript Podcast for convenient understanding

- Global attainment for your research

- Manuscript accessibility in different formats

( Pdf, E-pub, Full Text, Audio)

- Unceasing customer service

Track the below URL for one-step submission https://juniperpublishers.com/online-submission.php 